\title{
EVALUASI KESESUAIAN LAHAN PERTANAMAN PADI SAWAH IRIGASI KELOMPOK TANI MEKAR DESA TULUNG BALAK KECAMATAN BATANGHARI NUBAN KABUPATEN LAMPUNG TIMUR
}

\author{
Tahtia Sarasmi Astungkara, Tamaluddin Syam, Niar Nurmauli \& Ali Kabul Mahi \\ Jurusan Agroteknologi, Fakultas Pertanian Universitas Lampung \\ Jl.Prof. Soemantri Brodjonegoro, No.35, Bandar Lampung35145 \\ E-mail: tiasaras@yahoo.com
}

\begin{abstract}
ABSTRAK
Tanaman padi merupakan tanaman yang sangat penting di Indonesia dikarenakan sebagian besar penduduk Indonesia mengonsumsi beras sebagai bahan pangan pokok. Untuk mencapai produksi yang optimal, tanaman padi sebaiknya ditanam pada lahan yang sesuai dengan persyaratan tumbuh tanaman tersebut. Penilaian kesesuaian lahan sangatlah diperlukan guna mendapatkan informasi mengenai kualitas dan karakteristik lahan yang sesuai, sehingga dapat diketahui kelas kesesuaian lahan dan faktor pembatasnya, maka dapat ditentukan tingkat pengelolaan yang diperlukan. Penelitian bertujuan untuk mengevaluasi kesesuaian lahan kualitatif dan kuantitatif pertanaman padi sawah irigasi Kelompok Tani Mekar Desa Tulung Balak Kecamatan Batanghari Nuban Kabupaten Lampung Timur yang dilaksanakan pada Bulan Januari sampai Maret 2013 dengan menggunakan metode survei dan pendekatan evaluasi lahan secara paralel, yaitu melakukan analisis fisik lingkungan berdasarkan kriteria biofisik tanaman padi sawah irigasi dan analisis kelayakan usaha budidaya tanaman padi sawah irigasi dengan menilaiNet Present Value (NPV), Net Benefit Cost Ratio (Net B/C ratio) dan Internal Rate of Return (IRR) untuk data selama 4 musim tanam. Hasil penelitian menunjukkan, lahan pertanaman padi sawah irigasi Kelompok Tani Mekar Desa Tulung Balak Kecamatan Batanghari Nuban Kabupaten Lampung Timur termasuk kedalam kategori kelas kesesuaian lahan cukup sesuaidengan faktor pembatas berupa kejenuhan basa dan C-organik (S2 nr), dan secara finansial menguntungkan dan layak untuk dilanjutkan, kelayakan usaha ini dibuktikan dari hasil perhitungan yang menunjukkan bahwa nilai $N P V$ rata-rata sebesar Rp 49.725.671,-, Net B/C ratio rata-rata sebesar 2,93, dan IRR rata-rata sebesar23,82\% tahun ${ }^{-1}$.
\end{abstract}

Kata kunci: Evaluasi kesesuaian lahan, kelayakan usahatani, padi sawah.

\section{PENDAHULUAN}

Kebutuhan beras di Indonesia meningkat seiring dengan peningkatan laju pertumbuhan penduduk, namun hal ini tidak dibarengi dengan peningkatan kuantitas dan kualitas lahan padi sawah. Melihat kondisi seperti ini maka diperlukan suatu upaya dalam peningkatan produksi beras agar kebutuhan beras dapat terpenuhi (Aak, 1990).

Peningkatan laju pertumbuhan penduduk yang tidak dibarengi dengan peningkatan kuantitas dan kualitas lahan padi sawah merupakan suatu kendala dalam pemenuhan kebutuhan pangan nasional. Salah satu cara dalam meningkatkan produksi beras yaitu perlu adanya suatu usaha dalam menilai kesesuaian lahan secara kualitatif dan kuantitatif pada lahan pertanaman padi sawah. Penelitian ini dilakukan pada sawah irigasi Kelompok Tani Mekar Desa Tulung Balak Kecamatan Batanghari Nuban Kabupaten Lampung Timur yang merupakan lahan produktif, dimana produksi gabah tanaman padi Varietas Ciherang yang digunakan mampu mencapai 6,6 tha ${ }^{-1}$ dalam setiap musim tanam pada lahan seluas 15 ha. Penelitian bertujuan untuk menilai kesesuaian lahan secara kualitatif pertanaman padi sawah irigasi Kelompok Tani Mekar Desa Tulung Balak Kecamatan Batanghari Nuban Kabupaten Lampung Timur berdasarkam kriteria Djaenuddin dkk.(2003) dan mengevaluasi kesesuaian lahan secara kuantitatif dengan menganalisis nilai kelayakan finansial budidaya tanaman padi sawah irigasi pada lahan penelitian tersebut.

\section{BAHAN DAN METODE}

Penelitian dilakukan di lahan padi sawah irigasi milik Kelompok Tani Mekar Desa Tulung Balak dengan luas 15 ha yang terletak pada wilayah Kecamatan Batanghari Nuban, Kabupaten Lampung Timur. Lokasi 
penelitian berada pada koordinat 537451-537509 mT dan 9448375-9448283 mU. Penelitian dilakukan pada bulan Januari 2013 sampai dengan Maret 2013 dan analisis tanah dilakukan di Laboratorium Ilmu Tanah Fakultas Pertanian Universitas Lampung.

Alat-alat yang digunakan antara lain meteran, global positioning system (GPS), munsell Soil Color Chart, bor tanah, kantung plastik, kamera digital, alatalat tulis, dan alat-alat laboratorium. Bahan-bahan yang digunakan antara lain contoh tanah dan bahan-bahan kimia untuk analisis tanah di laboratorium.

Penelitian dilakukan dengan menggunakan metode survei evaluasi lahan secara paralel, yaitu melakukan evaluasi lahan kualitatif (biofisik) dan kuantitatif (finansial) secara bersamaan. Evaluasi lahan kualitatif dilakukan berdasarkan kriteria biofisik Djaenuddin dkk.(2003), sedangkan evaluasi lahan kuantitatif dilakukan dengan menghitung nilai kelayakan finansial dengan menghitung $N P V$, Net B/C Ratio, dan IRR (Ibrahim, 2003).

Pelaksanaan penelitian dilakukan dengan menggunakan beberapa tahap, yaitu: tahap persiapan, pengumpulan data, dan analisis data.

Tahap ini merupakan tahap studi pustaka, yaitu meneliti dan mengkaji sumber-sumber pustaka tentang keadaan lokasi penelitian sehingga diperoleh gambaran umum tentang lokasi penelitian, seperti data iklim dan karateristik lahan. Pada tahap ini dilakukan survei lapang secara kasar dan penentuan titik pengambilan contoh tanah yang mewakili secara keseluruhan berdasarkan keadaan lapang.

Data yang dikumpulkan meliputi data fisik dan data sosial ekonomi. Data fisik antara lain data fisik primer yaitu data yang diamati dan diukur langsung di lapang (drainase, bahan kasar, kedalam tanah, lereng, bahaya erosi, genangan, batuan dipermukaan dan batuan singkapan) dan data yang dianalisis di laboratorium (KTK tanah, basa-basa yang dapat dipertukarkan, $\mathrm{pH}$ tanah, C-organik dan tekstur tanah), sedangkan data fisik sekunder berupa suhu dan kelembaban udara diambil 10 tahun terakhir dari stasiun klimatologi setempat. Data sosial ekonomi meliputi data sosial ekonomi primer biaya produksi (benih, pupuk, pestisida), peralatan, tenaga kerja (pengolahan tanah, penanaman, pemupukan, penyiangan, panen, dll), dan pendapatan selama 4 musim tanam yang diperoleh petani pada lahan penelitian, sedangkan data sosial ekonomi sekunder berupa data luas panen dan hasil produksi gabah.

Analisis kesesuaian lahan kualitatif dilakukan dengan cara mencocokkan syarat tumbuh tanaman padi berdasarakan kriteria Djaenuddin dkk.(2003) dengan menilai karakteristik dan kualitas lahan di lapang, kemudian analisis kesesuaian lahan kuantitatif dilakukan analisis finansial dengan menghitung nilai $N P V, N e t B / C$ ratio dan $I R R$.

\section{HASIL DAN PEMBAHASAN}

Analisis kualitatif. Berdasarkan hasil pengumpulan data, baik data primer maupun data sekunder, maka didapatkan rata-rata suhu tahunan di daerah penelitian sebesar $27,35^{\circ} \mathrm{C}$ dan rata-rata kelembaban udara tahunan sebesar $82,9 \%$. Hasil pengamatan profil tanah di lapang menunjukkan bahwa drainase pada lahan penelitian dikategorikan agak terhambat, tekstur tanah termasuk dalam kelas liat, danbahan kasar tidak ditemukan $(0 \%)$. Kemudian dari hasil analisis laboratorium didapat bahwa KTK liat sebesar 18,1 Cmol $\mathrm{kg}^{-1}$, Kejenuhan basa sebesar 36,69\%, $\mathrm{pH} \mathrm{H}_{2} \mathrm{O}$ sebesar 5,52, danC-organik sebesar $0,84 \%$. Hasil analisis data didapat bahwa kelas kesesuaian lahan kualitatif untuk tanaman padi sawah irigasi pada lahan penelitian termasuk kedalam kategori kelas kesesuaian lahan cukup sesuai dengan faktor pembatas berupa kejenuhan basa dan C-organik (S2 nr) (Tabel. 1).

Analisis Kuantitatif. Biaya usahatani tanaman padi sawah irigasi pada lahan penelitian terdiri dari biaya tetap dan biaya variabel. Biaya tetap pada lahan penelitian terdiri dari biaya sewa lahan sebesar Rp 3.000.000,-, dan peralatan pertanian sebesar Rp $361.500,-$. Sedangkan, biaya variabel terdiri dari biaya benih sebesar Rp 165.000,-, pupuk kimia sebesar Rp 1.460.000,-, pupuk kandang sebesar Rp 200.000,-, insektisida sebesar Rp 80.000,-, dan biaya tenaga kerja borongan sebesar Rp 2.280.000,--

Penerimaan dari penjualan gabah kering giling pada tiap musim tanam selalu mengalami perubahan. Pada musim tanam pertama dan kedua diperoleh penerimaan rata-rata sebesar $\mathrm{Rp} 13.890 .680$,- dan Rp 13.251.200,- kemudian pada musim tanam ketiga dan keempat diperoleh penerimaan rata-rata sebesar Rp13.822.420,- dan Rp 13.478.500,-. Total penerimaan rata-rata usahatani padi sawah irigasi selama empat musim tanam adalah sebesar Rp 13.610.700,-.

Analisis Finansial. Analisis finansial dilakukan dengan menghitung nilai penerimaan bersih sekarang, nilai perbandingan antara penerimaan bersih dan biaya serta nilai tingkat pengembalian internal dengan menggunakan tingkat suku bunga yang berlaku dimasyarakat saat ini. Tingkat suku bunga yang berlaku diasumsikan sebesar 15\%. Berdasarkan hasil perhitungan data maka diperoleh rata-rata $N P V$ sebesar Rp 49.725.671, Net B/C sebesar 2,93 dan IRR sebesar $23,82 \%$ tahun $^{-1}$. Berdasarkan hasil perhitungan nilai 
Tabel 1. Evaluasi kesesuaian lahan aktual tanaman padi sawah irigasi pada lahan penelitian pertanaman padi sawah irigasi menurut kriteria Djaenudin dkk.(2003).

\begin{tabular}{|c|c|c|}
\hline $\begin{array}{l}\text { Persyaratan Penggunaan/ } \\
\text { Karakteristik Lahan }\end{array}$ & $\begin{array}{c}\text { Nilai } \\
\text { Karakteristik Lahan }\end{array}$ & $\begin{array}{c}\text { Kelas } \\
\text { Kesesuaian Lahan }\end{array}$ \\
\hline $\begin{array}{l}\text { Temperatur (tc) } \\
\text { Suhu tahunan rata-rata }\left({ }^{\circ} \mathrm{C}\right)\end{array}$ & 27,35 & $\mathrm{~S} 1$ \\
\hline $\begin{array}{l}\text { Ketersediaan air (wa) } \\
\text { Kelembaban }(\%)\end{array}$ & 82,9 & $\mathrm{~S} 1$ \\
\hline $\begin{array}{l}\text { Media perakaran }(\mathbf{r c}) \\
\text { Drainase } \\
\text { Tekstur } \\
\text { Bahan kasar }(\%) \\
\text { Kedalaman tanah }(\mathrm{cm})\end{array}$ & $\begin{array}{c}\text { Agak terhambat } \\
\text { Halus } \\
0 \\
>120\end{array}$ & $\begin{array}{l}\text { S1 } \\
\text { S1 } \\
\text { S } 1 \\
\text { S } 1\end{array}$ \\
\hline $\begin{array}{l}\text { Retensi hara (nr) } \\
\text { KTK liat }\left(\mathrm{cmolc} \mathrm{kg}^{-1}\right) \\
\text { Kejenuhan basa }(\%) \\
\text { pH } \mathrm{H}_{2} \mathrm{O} \\
\text { C-organik }(\%)\end{array}$ & $\begin{array}{c}18,1 \\
36,69 \\
5,52 \\
0,84\end{array}$ & $\begin{array}{l}\text { S } 1 \\
\text { S2 } \\
\text { S1 } \\
\text { S2 }\end{array}$ \\
\hline $\begin{array}{l}\text { Toksisitas (xc) } \\
\text { Salinit as (dS/m) }\end{array}$ & $<2$ & S 1 \\
\hline $\begin{array}{l}\text { Sodisitas (xn) } \\
\text { Alkalinitas/ESP (\%) }\end{array}$ & 12 & $\mathrm{~S} 1$ \\
\hline $\begin{array}{l}\text { Bahaya sulfidik (xs) } \\
\text { Kedalaman sulfidik }(\mathrm{cm})\end{array}$ & $>100$ & $\mathrm{~S} 1$ \\
\hline $\begin{array}{l}\text { Bahaya erosi (eh) } \\
\text { Lereng }(\%) \\
\text { Bahaya erosi }\end{array}$ & $\begin{array}{c}0 \\
\text { S angat rendah }\end{array}$ & $\begin{array}{l}\text { S } 1 \\
\text { S } 1\end{array}$ \\
\hline $\begin{array}{l}\text { Bahaya banjir (fh) } \\
\text { Genangan }\end{array}$ & F0 & $\mathrm{S} 1$ \\
\hline $\begin{array}{l}\text { Penyiapan lahan (lp) } \\
\text { Batuan dipermukaan }(\%) \\
\text { Singkapan batuan }(\%)\end{array}$ & $\begin{array}{l}0 \\
0\end{array}$ & $\begin{array}{l}\mathrm{S} 1 \\
\mathrm{~S} 1\end{array}$ \\
\hline $\begin{array}{l}\text { Kelas Kesesuaian Lahan } \\
\text { Sub Kelas Kesesuaian Lahan }\end{array}$ & & $\begin{array}{l}\mathrm{S} 2 \\
\mathrm{~S} 2 \mathrm{nr}\end{array}$ \\
\hline
\end{tabular}

$N P V$, nilai $N e t B / C$ ratio lebih besar dari 1 dan nilai $I R R$ lebih besar dari suku bunga yang diasumsikan, maka hasil tersebutmenunjukkan bahwa usaha budidaya tanaman padi sawah irigasi Kelompok Tani Mekar Desa Tulung Balak Kecamatan Batanghari Nuban Kabupaten Lampung Timur selama periode empat musim tanam(2011 -2012) menguntungkan dan layak untuk dilanjutkan.

Berdasarkan hasil penelitian yang telah dilakukan pada lahan pertanaman padi sawah irigasi baik secara langsung di lapang maupun analisis di laboratorium. Maka, didapat dua faktor pembatas berupa kejenuhan basa dan C-organik yang masuk kedalam kategori kelas kesesuaian lahan cukup sesuai (S2 nr).

Kejenuhan basa $(\mathrm{KB})$ merupakan perbandingan antara kation basa $\left(\mathrm{Ca}^{2+}, \mathrm{Mg}^{2+}, \mathrm{K}^{+}\right.$, dan, $\left.\mathrm{Na}^{+}\right)$dengan kapasitas tukar kation (KTK) yang dinyatakan dalam persen (\%). Nilai kejenuhan basa pada lahan penelitian sebesar 36,69\% sehingga termasuk kedalam kategori kelas kesesuaian lahan cukup sesuai (S2).

Rendahnya kejenuhan basa pada lahan penelitian disebabkan adanya kation asam $\left(\mathrm{H}^{+}\right.$dan $\left.\mathrm{Al}^{3+}\right)$ yang menggantikan kation basa dalam kompleks jerapan kation dengan cara membebaskan kation $\mathrm{Ca}^{2+} \mathrm{dan} \mathrm{Mg}^{2+}$ ke dalam larutan tanah yang selanjutnya dapat tercuci 
(leaching) karena dibawa hanyut oleh air perkolasi yang dilepaskan ke dalam horizon tanah. Hilang atau berkurangnya kation basa $\left(\mathrm{Ca}^{2+}, \mathrm{Mg}^{2+}, \mathrm{K}^{+}\right.$, dan, $\left.\mathrm{Na}^{+}\right)$ akibat sering terjadinya pencucian (leaching) pada lahan penelitian akan mengikis kation basa yang merupakan unsur hara yang dibutuhkan tanaman dalam menunjang kesuburan tanah.

Kejenuhan basa (KB) sering dianggap sebagai petunjuk tingkat kesuburan tanah, dimana tanah yang memiliki KB tinggi akan lebih mudah melepas basa-basa yang dapat dipertukarkan dalam tanah. Tanah dengan nilai KB tinggi menunjukkan kandungan kation basa juga tinggi dan sebagai pertanda belum banyak mengalami pencucian (Ansyori dkk.,2010). Menurut Salam (2011) kejenuhan basa (KB) yang rendah disebabkan oleh menurunnya atau hilangnya kation basa $\left(\mathrm{Ca}^{+}, \mathrm{K}^{+}, \mathrm{Mg}^{2+}\right.$, $\mathrm{Na}^{+}$) yang merupakan unsur hara yang diperlukan tanaman dan sangat mudah tercuci oleh aliran air sehingga kondisi tanah yang mempunyai nilai KB rendah menunjukkan ketersediaan unsur hara yang rendah, artinya tanah tersebut telah banyak mengalami pencucian. Sarief (1986) menyatakan bahwa untuk meningkatkan kejenuhan basa (KB) dapat dilakukan dengan cara meningkatkan kation basa $\left(\mathrm{Ca}^{+}, \mathrm{K}^{+}, \mathrm{Mg}^{2+}\right.$, $\mathrm{Na}^{+}$) yang dapat diperoleh melalui pengapuran jenis dolomit $\left(\mathrm{CaMg}\left(\mathrm{CO}_{3}\right)_{2}\right)$ karena kapur jenis ini jika terhidrolisis akan menghasilkan ion hidroksil yang dapat meningkatkan kation basa dengan suplai kation $\mathrm{Ca}^{2+}$ dan $\mathrm{Mg}^{2+}$ yang tinggi.

Faktor pembatas lain yang didapat melalui analisis laboratorium yaitu kandungan C-organik yang tergolong rendah yaitu sebesar $0,84 \%$ sehingga termasuk kedalam kategori kelas kesesuaian lahan cukup sesuai (S2).

Penyebab rendahnya kandungan C-organik pada lahan penelitian dikarenakan petani tidak mengembalikan jerami padi ke lahan pertanian, tetapi hanya memberi bahan organik berupa pupuk kandang sebanyak $1 \mathrm{tha}^{-1}$ per musim tanam. Dari hasil analisis tanah didapatkan bahwa bahan organik yang diberikan belum dapat mencukupi kebutuhan kandungan C-organik yang ideal berdasarkan kriteria kesesuaian lahan tanaman padi menurut Djaenuddin dkk., 2003. Oleh sebab itu, untuk meningkatkan kandungan C-organik pada lahan penelitian dapat dilakukan dengan mengembalikan semua jerami padi yang dihasilkan dari lahan pertanian tersebut.

Karama et al. (1990, dalam Nursyamsi dkk., 2000) menyatakan bahwa bahan organik memiliki peran penting dalam memperbaiki sifat fisika, kimia, dan biologi tanah antara lain memperbaiki agregasi dan permeabilitas tanah, meningkatkan ketersediaan beberapa unsur hara, dan sebagai sumber energi utama bagi aktivitas mikroorganisme tanah. Mengingat begitu penting peranan bahan organik sebagai peningkat kandungan $\mathrm{C}$-organik dalam tanah, maka pemberian bahan organik pada lahan pertanian yang kesuburan tanahnya mulai menurun menjadi amat penting dalam menjaga kelestarian sumberdaya lahan pertanian tersebut. Meirong dkk. (2011) menyatakan bahwa pengaruh pemberian bahan organik jangka panjang selama 18 tahun pada lahan pertanaman padi sawah kondisi tropis, dapat meningkatkan kandungan C-organik sebesar 19,2\% dibandingkan tanpa pemberian bahan organik. Rendahnya kandungan C-organik di daerah tropis disebabkan oleh tingkat pelapukan bahan organik yang sangat tinggi, sehingga turn over $\mathrm{C}$-organik dalam tanah berlangsung singkat.

Tingkat pelapukan bahan organik dipengaruhi oleh iklim berupa suhu dan kelembaban udara. Semakin tinggi suhu udara akan semakin banyak konsumsi oksigen dan akan semakin cepat pula proses dekomposisi bahan organik. Suhu udara yang berkisar antara $30-60^{\circ} \mathrm{C}$ menunjukkan aktivitas pengomposan yang cepat. Suhu yang lebih tinggi dari $60^{\circ} \mathrm{C}$ akan membunuh sebagian mikroba dan hanya mikroba thermofilik saja yang akan tetap bertahan hidup. Makin ke daerah dingin, kadar bahan organik dan $\mathrm{N}$ makin tinggi. Jika kelembaban efektif meningkat, maka kadar bahan organik dan N juga bertambah. (Brady and Weil, 2008).

Untuk mengetahui tingkat kelayakan usahatani padi sawah irigasi digunakan analisis $N P V, N e t B / C$ ratio, dan IRR. Dari hasil pengolahan data, diperoleh nilai rata-rata $N P V$ Kelompok Tani Mekar sebesar Rp 49.725.671,-, yang berarti bahwa selama 4 musim tanam usahatani padi sawah irigasi, petani akan mendapatkan nilai pendapatan bersih sebesar nilai $N P V$ yang diperoleh. Karena nilai $N P V$ yang diperoleh $>0$ maka dapat dikatakan bahwa usahatani padi sawah irigasi tersebut layak untuk diusahakan.

Net $B / C$ ratio (rasio biaya manfaat bersih) adalah nilai manfaat yang bisa didapatkan dari proyek atau usaha setiap kita mengeluarkan biaya sebesar satu rupiah untuk proyek atau usaha tersebut. Nilai penerimaan bersih dan biaya (Net B/C ratio) yang diperoleh pada usahatani padi sawah irigasi Kelompok Tani Mekar yaitu sebesar 2,93 . Berdasarkan besarnya nilai $\mathrm{Net} B / \mathrm{C}$ ratio yang diperoleh memiliki nilai lebih besar dari $1(>1)$, maka dapat dikategorikan bahwa usahatani padi sawah irigasi kelompok tani tersebut adalah layak untuk diusahakan.

Dari hasil perhitungan nilai $I R R$ yang telah dilakukan, maka didapat nilai rata-rata $I R R$ Kelompok Tani Mekar sebesar 23,82 \% tahun $^{-1}$, dimana hasilnya lebih tinggi dari tingkat suku bunga yang telah ditentukan yaitu sebesar $15 \%$ tahun $^{-1}$. Meskipun kesesuaian lahan 
kualitatifnya termasuk kedalam kategori kelas kesesuaian lahan cukup sesuai (S2nr), tetapi pada segi kelayakan finansial usahatani padi sawah irigasi di lokasi penelitian termasuk menguntungkan dan layak untuk dilanjutkan.

\section{KESIMPULAN}

Berdasarkan hasil penelitian yang telah dilakukan dapat disimpulkan bahwa kelas kesesuaian lahan pertanaman padi sawah irigasi Kelompok Tani Mekar Desa Tulung Balak Kecamatan Batanghari Nuban Kabupaten Lampung Timur menurut kriteria Djaenuddin dkk. (2003) adalah cukup sesuai dengan faktor pembatas berupa kejenuhan basa dan C-organik (S2nr). Usaha budidaya tanaman padi sawah irigasi Kelompok Tani Mekar Desa Tulung Balak, Kecamatan Batanghari Nuban, Lampung Timur secara finansial menguntungkan dan layak untuk dilanjutkan. Hal ini dibuktikan dari hasil perhitungan yang menunjukkan bahwa nilai $N P V$ ratarata sebesar Rp 49.725.671,-, Net $B / C$ rata-rata sebesar 2,93, dan IRR rata-rata sebesar 23,82\% tahun ${ }^{-1}$ yang nilainya lebih besar dari tingkat suku bunga yang berlaku saat ini yang diasumsikan sebesar $15 \%$ tahun $^{-1}$.

\section{DAFTAR PUSTAKA}

Aak. 1990. Budidaya Tanaman Padi. Kanisius. Yogyakarta. $172 \mathrm{hlm}$.

Ansyori, Sudarsono, R. Poerwanto, and Darmawan.2010. Land Suitability Criteria for Intensively Managed Cavendish Banana Crop in
Way Kambas East Lampung, Indonesia. Jurnal Tanah Tropika. 15(2): 159-167.

Brady, N.C dan R.R Weil. 2008. The Nature and Properties of Soil. Pearson education, Inc. United States of America. 965 p.

Djaenuddin, D., H. Marwan, H. Subagyo, dan A. Hidayat. 2003. Kriteria Kesesuaian Lahan Untuk Komoditas Pertanian. Departemen Pertanian. $264 \mathrm{hlm}$.

Ibrahim, M. Y. 2003. Studi Kelayakan Bisnis. (Edisi Revisi). PT Rineka Cipta, Jakarta. 249 hlm.

Meirong, LV., Zhongpei, Li., Yuping, Che., FX Han., Ming Liu. 2011. Soil Organic, Nutrient, Microbial Biomass, and Grain Yield of Rice (Oryza sativa L.) after 18 Year of Fertilizer Application to an Infertile Paddy Soil. Journal Biol Fertil Soil. 47: 777-783.

Nursyamsi, D., L.R. Widowati, D. Setyorini, dan J. Sri Adiningsih. 2000. Pengaruh Pengolahan Tanah, Pengairan Terputus, dan Pemupukan Terhadap Produktivitas Lahan Sawah Bukaan Baru Pada Inceptisol dan Ultisols Muarabeliti dan Tatakarya. Jurnal Tanah dan Iklim. 18: 29-38.

Salam, A.K. 2011. Ilmu Tanah Fundamental. Global Madani Press. Bandar Lampung. $362 \mathrm{hlm}$.

Sarief, S. 1986. Fisika-Kimia Tanah Pertanian. Pustaka Buana. Bandung. $220 \mathrm{hlm}$. 